\title{
INDÚSTRIA CULTURAL E A DIALÉTICA DO ESCLARECIMENTO: IMPLICAÇÕES PARA O TRABALHO DOCENTE NA EDUCAÇÃO FÍSICA ESCOLAR
}

\author{
INDUSTRIA CULTURAL Y LA DIALÉTICA DE LA ACLARACIÓN: IMPLICACIONES \\ PARA EL TRABAJO DOCENTE EN LA EDUCACIÓN FÍSICA ESCOLAR
}

\section{CULTURAL INDUSTRY AND DIALECTICS OF CLARIFICATION: IMPLICATIONS FOR TEACHING WORK IN SCHOOL PHYSICAL EDUCATION}

\author{
Flávia Regina Schimanski dos SANTOS ${ }^{1}$ \\ Fernanda Neri de OLIVEIRA ${ }^{2}$ \\ Karina de Toledo ARAÚJO ${ }^{3}$ \\ Rovilson JOSÉ DA SILVA ${ }^{4}$
}

RESUMO: O objetivo deste estudo, de cunho qualitativo, é refletir sobre a Educação Física Escolar enquanto componente curricular constituída por conhecimentos e saberes que integram a formação humana à luz Teoria Crítica da Sociedade, com fundamentos na concepção educacional Crítico-Emancipatória, elaborada por Elenor Kunz. O percurso metodológico é uma pesquisa bibliográfica, que analisa as interferências da Indústria Cultural na conjuntura da sociedade atual e seus impactos para o campo educacional, especificamente nas aulas de Educação Física. A discussão contribui para pensar sobre a ruptura do ensino com vistas ao esclarecimento e a emancipação.

PALAVRAS-CHAVE: Educação física. Indústria cultural. Esclarecimento.

RESUMEN: El objeto de este estudio, de cuño cualitativo, es reflexionar sobre la Educación Física Escolar como componente curricular constituida por conocimientos y saberes que interactúan con la formación humana a la luz de la Teoría Crítica de la Sociedad, con fundamentos en la concepción educacional Crítico-Emancipadora, elaborada por Elenor Kunz. El proceso metodológico es una investigación bibliográfica, que analiza las interferencias de la Industria Cultural en la coyuntura de la sociedad actual y sus impactos para el campo educacional, específicamente en las clases de Educación Física. La discusión contribuye para pensar sobre la ruptura de la enseñanza en pos de la aclaración y la emancipación.

\footnotetext{
${ }^{1}$ Universidade Estadual de Londrina (UEL) Londrina - PR - Brasil. Mestranda do Programa de Pós-Graduação em Educação da UEL. ORCID: https://orcid.org/0000-0002-4583-0193. Lattes: http://lattes.cnpq.br/0721995525757781.E-mail: flaviaschimanski@hotmail.com

${ }^{2}$ Universidade Estadual de Londrina (UEL) Londrina - PR - Brasil. Mestranda do Programa de Pós-Graduação em Educação da UEL. Lattes: http://lattes.cnpq.br/7330981636023755. E-mail: nanda.neri@ hotmail.com ${ }^{3}$ Universidade Estadual de Londrina (UEL) Londrina - PR - Brasil. Docente do curso de Licenciatura em Educação Física, Departamento Estudos do Movimento Humano (UEL). Lattes: http://lattes.cnpq.br/0453297121251055 E-mail: karina.araujo@uel.br

${ }^{4}$ Universidade Estadual de Londrina (UEL), Londrina - PR - Brasil. Docente do Departamento de Educação. Pósdoutorado em Ciência da Informação (UNESP/Marília). ORCID: https://orcid.org/0000-0002-8756-9421. Lattes: http://lattes.cnpq.br/7093169997866163. E-mail: rovilson@uel.br

RIAEE - Revista Ibero-Americana de Estudos em Educação, Araraquara, v. 14, n. esp. 4, p. 1924-1943, dez., 2019. E-ISSN: $1982-5587$. DOI: https://doi.org/10.21723/riaee.v14iesp.4.12919 
PALABRAS CLAVE: Educación Física. Industria cultural. Aclaración.

ABSTRACT: The aim of this qualitative study is to reflect on School Physical Education as a curricular component consisting of knowledge and knowings that integrate human formation in light of Critical Theory of Society, based on the Critical-Emancipatory educational conception, elaborated by Elenor Kunz. The methodological course is a bibliographic research that analyzes the interferences of the Cultural Industry in the conjuncture of the current society and its impacts for the educational field, specifically in the Physical Education classes. The discussion contributes to thinking about the rupture of teaching with a view to enlightenment and emancipation.

KEYWORDS: Physical education. Cultural industry. Clarification.

\section{Introdução}

É comum que no ideário da sociedade a concepção de Educação Física na escola tenha a sua função atrelada a uma área de atividade prática, exclusivamente técnica e de conteúdo esportivista. Além disso, também há um pensamento sobre as aulas de Educação Física como se um de seus objetivos fosse dispor um espaço e horário livre das atividades de 'sala de aula com conteúdos teóricos' ou para que os demais professores - das outras disciplinas - tenham tempo para o cumprimento das horas-atividades, sem o prejuízo de lacunas com tempo livre para os estudantes. No entanto, neste artigo, buscaremos apresentar a importância da área da Educação Física enquanto componente curricular constituída por conhecimentos e saberes que integram a formação humana, a partir de reflexões das contribuições da Teoria Crítica da Sociedade $^{5}$ para o trabalho docente na Educação Física, com fundamentos na concepção educacional Crítico-Emancipatória, elaborada por Elenor $\mathrm{Kunz}^{6}$, como uma proposta pedagógica para o ensino dos conteúdos da Educação Física e a crítica das formas tradicionais de seu ensino na escola.

As categorias Esclarecimento e Emancipação são essenciais na Teoria Crítica e as entendemos como orientações para problematizar e apresentar a importância da Educação

5 Trata-se de uma abordagem teórica elaborada pelos filósofos da escola de Frankfurt. Seus principais representantes são Theodor W. Adorno e Max Horkheimer. Os estudos dos teóricos frankfurtianos se contrapõem à teoria tradicional, pois analisam criticamente as condições sociopolíticas e econômicas, visando a transformação da sociedade por meio do pensamento crítico, como uma possibilidade para a emancipação humana.

${ }^{6}$ A perspectiva elaborada por Kunz possui influências dos filósofos da Escola de Frankfurt, especificamente Theodor W. Adorno, Max Horkheimer e Herbert Marcuse (da primeira geração) e Jürgen Habermas (segunda geração). O autor, apropria-se de fortes conceitos da Teoria Crítica, como Emancipação e Esclarecimento, visando a ruptura com o modelo tradicional de ensino da Educação Física Escolar. Com a finalidade de uma formação de sujeitos críticos e autônomos para transformação da realidade em que estão inseridos.

RIAEE - Revista Ibero-Americana de Estudos em Educação, Araraquara, v. 14, n. esp. 4, p. 1924-1943, dez., 2019. E-ISSN: $1982-5587$. DOI: https://doi.org/10.21723/riaee.v14iesp.4.12919 
Física na escola, sobretudo os desafios a serem superados na busca de um ensino emancipatório, para além do que essa disciplina representa quando pautada em uma perspectiva mais técnica e tradicional de ensino.

O movimento crítico na área da Educação Física escolar teve seu marco inicial na década de 1980, com novas tendências pedagógicas ${ }^{7}$ com pesquisadores da área que se aprofundaram em seus estudos com a intenção romper com o modelo tradicional e, direcionar o ensino dos conteúdos da Educação Física no espaço escolar com vistas a superação das dicotomias mente/corpo que impedem a concepção da totalidade do ser, o dividindo em corpo e mente, como se fossem dissociáveis. De acordo com a cultura de determinado lugar e contexto social, há uma concepção de corpo que guia o comportamento dos sujeitos, como apresentam Berte e Martins (2016) imagens do corpo que foram construídas pela tradição ocidental, como 'corpo máquina', 'corpo recipiente', 'corpo tábula rasa', ‘corpo morada da alma/espírito', concepções ainda são disseminadas em espaços acadêmicos, religiosos, educacionais.

A dualidade de corpo de mente, justifica a Educação Física como uma área sem conhecimento, uma área de atividade apenas corporal, em que as ações cognitivas não acontecem, por considerar que a inteligência, a capacidade de refletir e abstrair é requerida somente nas disciplinas como Matemática, Geografia, Língua Portuguesa, entre outras. Conforme Ghiraldelli Jr. (2007), a concepção de corpo não está ligada a uma consciência, ou a um arcabouço de ideários. Por essa razão, compreendemos que a educação tem o papel de promover a emancipação dos sujeitos, resistindo às concepções que limitam os sujeitos de viver a sua totalidade.

\section{Industria Cultural e Educação: interfaces entre dominação e emancipação}

Max Horkheimer e Theodor W. Adorno empregaram pela primeira vez o termo Indústria Cultural no livro "Dialética do Esclarecimento ” em 1947, substituindo a expressão ‘cultura de massa' adotada até então, pois perceberam que esta remetia a uma ideia de algo elaborado pela massa de forma espontânea. A cultura de massa, então, demonstrava um significado de que foi criada a partir da solicitação das massas (MAAR, 2003).

${ }^{7}$ O coletivo de autores composto por Carmen L. Soares, Celi N. Zülke Taffarel, Elizabeth Varjal, Lino Castellani Filho, Micheli O. Escobar e Valter Bracht, elaboraram a proposta crítico-superadora, de cunho marxista, concebendo a Educação Física como disciplina que trata pedagogicamente temas da Cultura Corporal. (SOARES, 1992); João Batista Freire na perspectiva construtivista baseada nos estudos de Jean Piaget, a qual defende que as habilidades motoras devem ser desenvolvidas num contexto de jogo e brincadeira, de acordo com o estágio de desenvolvimento cognitivo da criança; Elenor Kunz, com a abordagem crítico-emancipatória, com objetivo de formar sujeitos autônomos e críticos e romper com o ensino voltado para o esporte de rendimento.

RIAEE - Revista Ibero-Americana de Estudos em Educação, Araraquara, v. 14, n. esp. 4, p. 1924-1943, dez., 2019. E-ISSN: 1982-5587. DOI: https://doi.org/10.21723/riaee.v14iesp.4.12919 
Já a Indústria Cultural denota um sentido que se refere a mercantilização da cultura, sua banalização e reificação. Como apresenta Costa (2013, p. 136), a "indústria cultural é fruto da oportunidade de expansão da lógica do capitalismo sobre a cultura”. Desse modo, a lógica do capital criou e determinou a estrutura social por meio de um sistema político e econômico, tendo a finalidade de produzir bens de cultura, como por exemplo os filmes, livros, música popular, programas de TV, mercadorias e estratégias de controle social. Portanto, a Indústria Cultural detém o controle sobre a cultura, transforma as pessoas em consumidores de mercadorias culturais e assim consegue produzir em grande escala, retirando dos sujeitos os interesses por fontes que os incentivem a pensar criticamente. Sendo assim, a Indústria Cultural é um termo empregado para um modo de se fazer cultura, partindo do pressuposto de uma produção industrial.

Nesse sentido, refere-se a um processo de produção contínua de conteúdos atrativos tendo como fim a lucratividade e a alienação dos sujeitos, desvalorizando as manifestações culturais e implantando a sua ideologia na sociedade, de modo a seduzir os consumidores atraindo a total atenção para tudo que é consumível e desperte prazer, assim dificilmente irão se rebelar com as condições sociais em que estão inseridos. A capacidade de padronização de comportamentos que a Indústria Cultural possui traz consigo uma racionalidade técnica de dominação, na qual todos os elementos característicos do mundo industrial moderno exercem um papel específico, ou seja, o de portadores da ideologia dominante.

Com o objetivo de conduzir os consumidores à dependência, a sociedade do consumo cria nos seres humanos, desejos que estão longe de serem necessidades humanas, são ilusões que passam a ser desejos sociais. Essa construção de necessidades e padronização de desejos são propagadas pelos meios de comunicação de massa e as instituições sociais ${ }^{8}$ como, por exemplo, a escola. As propagandas, uma das formas de se propagar os desejos, são tão sedutoras que despertam a convicção da necessidade de qualquer produto, por mais supérfluo que seja, devido a alienação ${ }^{9}$ que integra as massas. Para Horkheimer e Adorno (1985):

[...]criando "necessidades" ao consumidor (que consumidor deve contentar-se com o que lhe é oferecido), a indústria cultural organiza-se para que ele compreenda sua condição de mero consumidor, ou seja, ele é apenas e tão somente um objeto daquela indústria. Desse modo, instaura-se a dominação natural e ideológica (HORKHEIMER; ADORNO, 1985, p. 46).

\footnotetext{
${ }^{8}$ Aparelhos ideológicos de estado (AIE). Conceito de Louis Althusser (1987).

${ }^{9}$ Para Karl Marx (1844) o capitalismo produz a alienação do homem por meio da divisão do trabalho, afastandose de si mesmo e dos outros homens na medida em que sua essência humana é desconsiderada.

RIAEE - Revista Ibero-Americana de Estudos em Educação, Araraquara, v. 14, n. esp. 4, p. 1924-1943, dez., 2019. E-ISSN: $1982-5587$. 
O conceito de Indústria Cultural não só se mantém atual (nesta segunda década do século XXI), como possui uma certa relevância no que se refere a crítica das condições sociais que deram fundamentação a universalização da semiformação (Halbbildung). Zuin (2001) compreende que esse conceito se dá justamente pela tentativa de oferecimento de uma formação educacional que pareça ser voltada para o ensino emancipatório, mas que, na verdade, direciona para a reprodução dos padrões hegemônicos da sociedade, como para a manutenção da barbárie $^{10}$. Ivo Tonet (2005) explica que o ensino educativo está pautado na formação para a cidadania. Porém, o conceito de cidadania e forma como são transmitidos os valores e normas, são na verdade, uma falsa ideia de liberdade, pois, a estrutura da sociedade formada por cidadãos divididos em classes sociais, consequentemente, resulta na manutenção das desigualdades sociais. A lógica do capital em anunciar a cidadania, promove aos sujeitos a falsa sensação de igualdade, por isso, a educação é utilizada como um instrumento de semiformação para distanciar os sujeitos da emancipação humana.

Bueno (2007) elucida que a análise adorniana sobre semiformação ${ }^{11}$, apresenta características da personalidade autoritária, tornando a semicultura uma esfera do ressentimento. Os sujeitos passam a se revoltar quando não conquistam o que lhes é prometido ou o que idealizaram, se frustram e assim destilam o sentimento de ressentimento por meio de ações contra a própria cultura. Para a educação, a visão pragmática que mantém a semicultura gera "[...] negação prévia de toda possibilidade formadora que possa ter como objetivo algo mais além da aceitação inflexível da instrumentalização da vida" (BUENO, 2007, p. 306).

A indústria cultural permanece sendo a indústria da diversão, ou seja, seu controle sobre os consumidores é mediado pela diversão e entretenimento. Inclusive no ambiente escolar é visível a presença da lógica do consumismo, da necessidade de estímulo e resistência a tudo aquilo que não se possa aprender ou fazer rápido.

A questão da Indústria Cultural, da técnica e a sua participação na sociedade contemporânea, que por Adorno é tratada, nos traz contribuições importantes para analisar a sua interferência que ocorre também no decorrer do processo de ensino e aprendizagem na formação escolar. Pucci (2001) explica que Adorno viveu a presença da técnica até no final dos anos 1960 e percebeu que o desenvolvimento tecnológico deu origem a diversas invenções,

${ }^{10}$ Em "Educação após Auschwitz" Adorno se refere à barbárie como os horrores provocados pelo holocausto. Para o autor, a barbárie originou-se da inflexão dos perseguidores a partir das estruturas psicológicas e sociais dos sujeitos.

${ }^{11}$ Conceito da Teoria Crítica que significa uma formação limitada, sem reflexão. "O pensamento perde o fôlego e limita-se à apreensão do factual isolado. Rejeitam-se as relações conceituais porque são um esforço incômodo e inútil. (ADORNO; HORKHEIMER, 1947, p. 93)

RIAEE - Revista Ibero-Americana de Estudos em Educação, Araraquara, v. 14, n. esp. 4, p. 1924-1943, dez., 2019. E-ISSN: 1982-5587. 
possibilitando condições de avanços extraordinários para diversas instâncias da sociedade, dentre elas, a educação. No entanto, toda essa tecnologia continuou a serviço do capital e da exclusão dos indivíduos, porque os mais poderosos socialmente possuem controle dos aparatos tecnológicos, principalmente no que se refere à manutenção da ordem social que os favorece, como a dominação da classe trabalhadora.

Devido a sua função educativa, a escola acaba se tornando um instrumento de formação de concepções relativas à lógica dominante. Como parte integrante da sociedade, também abriu portas para a tecnologia, que pode ser aproveitada como um potencializador do processo de ensino e aprendizagem, podendo ser utilizada como estratégia de atividade e de interação.

No entanto, aceitar a tecnologia plenamente significa, para Pucci (2001a, p. 17), aderir aos paradoxos que a [...] "civilização, ambígua em si mesma, lhe impinge a todo momento, como, por exemplo, ser escravo de sua própria criação, deixar-se apagar pelo sistema que ele mesmo projetou". A experiência formativa, que exige silêncio e afinidade com os objetos, acaba empobrecida, de maneira paulatina por parte de seu anacronismo, isto é, pelo fato de não produzir coisas úteis para a formação e para o mercado. Na escola, formar os educandos tem o significado de criar condições para que eles realmente apreendam o sentido das forças de formação e das inquietações vivas, em tensão com as questões econômicas, sociais, culturais e políticas que interferem em seu cotidiano.

Ainda dialogando com Pucci (2005), o ensino precisa abranger o diálogo com os clássicos que ajudaram no processo de construção da cultura, da ciência e da história da humanidade, afim de que os sujeitos possam, a partir disso, tecer análises e reflexões sobre os problemas e desafios de seu próprio tempo. Os impactos frutos da ciência e das novas tecnologias, no que tange as transformações na forma de pensar, de ser, agir e se comportar do indivíduo, devem fazer parte de sua formação escolar, incentivando sua capacidade de reflexão, de pensamento crítico e consciente. A nossa defesa é por uma educação transformadora, não no sentido utópico, mas de possibilitar condições para a existência, para compreender o mundo e a estrutura social, analisando o contexto atual, para ser um sujeito ativo, gestor de suas ações e não um mero expectador das imposições e padrões sociais.

É urgente a necessidade de compreendermos e fazermos uma educação em consonância com seu tempo, espaço e, principalmente, com as necessidades dos atores e atrizes sociais que vivem na sociedade contemporânea. A educação nos é essencial e pode desempenhar diferentes papéis que dependem diretamente do objetivo almejado, objetivo este que pode ser a adaptação das pessoas às situações dadas ou a emancipação humana (ARAÚJO, 2013, p. $5165)$. 
Conquistar um ensino emancipatório necessita, principalmente, da ação do professor. Para tanto, o trabalho docente necessita ser intencional e planejado, visando não apenas a transmissão dos conhecimentos científicos, mas sobretudo, estabelecer por meio de práticas pedagógicas, um espaço formativo composto por um processo de ensino e aprendizagem voltado para a emancipação dos sujeitos. Contudo, essa almejada ação docente depende diretamente da formação de professores, da viabilização de condições formativas para que o profissional da docência estabeleça, por meio de suas práticas pedagógicas, um espaço formativo voltado para a emancipação dos sujeitos.

A grande contradição da educação - amplamente mencionada por diversos estudiosos está enraizada na sua capacidade de ensinar tanto para a resistência aos ditames desiguais, como promover a manutenção da estrutura social vigente, isto é, formar para a alienação ou para a emancipação. A Indústria Cultural, já integrada na realidade escolar, tem exercido fortes interferências no desenvolvimento dos estudantes, gerando consequências na postura destes. Os aparatos tecnológicos utilizados de maneira consciente e adequada, podem ser ótimas ferramentas para o processo de ensino e aprendizagem. Entretanto, o acesso desses recursos de forma descontrolada pode ocasionar o distanciamento do ensino para a emancipação.

As novas gerações estão cercadas de inovações tecnológicas, existem fatores positivos, mas para a educação surgiram algumas problemáticas. Como por exemplo, a resistência dos estudantes a leituras mais longas como em livros, pois esta geração está acostumada com a rapidez. Com a tecnologia em suas mãos para pesquisar sobre tudo a qualquer momento e obter informações rápidas é o que os interessa. O problema não está na agilidade do acesso. Quando as informações são mais valiosas que o conhecimento, que é mais elaborado, complexo e exige leituras, o sujeito centra-se nos saberes do senso comum. Portanto, aqui encontramos um dos objetivos da educação, o de despertar nos estudantes a busca por conhecimentos - os construídos culturalmente, os de si e do mundo - que proporcionem a saída da passividade, da alienação e das diversas formas de dominação para a emancipação humana.

\section{Dialética do Esclarecimento e Teoria Crítico-Emancipatória}

O termo esclarecimento que aqui anunciamos, tem como principal base o filósofo Imannuel Kant, que tece reflexões relativas ao conceito de esclarecimento em seu ensaio originalmente publicado em alemão Beantwortung der Frage: Was ist Aufklärung? (Respondendo à Pergunta: o que é Esclarecimento? (1784). O livro "Immanuel Kant: Textos Seletos" (2010) reúne os escritos do autor com uma tradução para a Língua Portuguesa. 
Encontramos assim, no ensaio "Respondendo à Pergunta: o que é Esclarecimento?". Uma elucidação do pensamento kantiano que já declara o sentido de liberdade e de emancipação intelectual dos sujeitos. "Esclarecimento (Aufklärung) é a saída do homem de sua menoridade, da qual ele próprio é culpado" (KANT, 1985, p. 102). Essa menoridade se refere a incapacidade de fazer algo por si próprio a partir do seu entendimento e depender do direcionamento de outros, a falta de entendimento é a falta de esclarecimento.

Kant (1985), ainda explica a facilidade que é ser dependente de outros. Para o homem é cômodo não precisar pensar, se desgastar e agir quando se tem alguém que o faça, no caso os tutores. Essa relação se tornou tão natural, que os tutores domesticaram os outros sujeitos para que não saíssem da direção determinada por eles, os faziam acreditar que são incapazes de caminhar sozinhos. Trazendo essa reflexão para a educação, especificamente no espaço escolar, os professores devem encorajar os estudantes a buscarem o esclarecimento, com um direcionamento que demonstre que eles podem ser sujeitos autônomos. O mesmo autor aponta, para que um público se esclareça é necessário que tenham liberdade.

Eis aqui por toda a parte a limitação da liberdade. Que limitação, porém, impede o esclarecimento? Qual não o impede, e até mesmo o favorece? Respondo: o uso público de sua razão deve ser sempre livre e só ele pode realizar o esclarecimento entre homens (KANT, 1985, p. 104).

A Indústria Cultural determina a razão instrumental ${ }^{12}$ na sociedade, visa impossibilitar os homens de pensar de acordo com a razão objetiva, isto é, a razão que os impede de pensar por si próprio e os torna suscetíveis à alienação. No entanto, a intenção de Kant (1985) em superar as imposições da Indústria Cultural por meio do potencial libertador do esclarecimento, não aconteceu porque esse esclarecimento se instrumentalizou. Essa reflexão integra a obra Dialética do Esclarecimento publicada em 1947, elaborada por Max Horkheimer e Theodor W. Adorno, em que os autores questionam como o esclarecimento, o iluminismo proposto por Kant, permitiu os desastres nazistas, já que as massas não pensaram criticamente e ainda consentiram os horrores. Para Horkheimer e Adorno (1947), o iluminismo é um mecanismo de mistificação das massas, por universalizar o conhecimento, resultando na dominação do saber vigente. $\mathrm{O}$ esclarecimento kantiano, portanto, molda o pensar, assim não oferece condições dos sujeitos perceberem que os avanços científicos criaram formas de exploração permanente. No capítulo “A Indústria Cultural: o esclarecimento como mistificação das massas” (ADORNO;

${ }^{12}$ Instrumentalização da razão, em que ciência é transformada em instrumento de dominação e controle em nome de um suposto progresso técnico preconizado pela sociedade tecnocrática. (ADORNO; HORKHEIMER, 1985).

RIAEE - Revista Ibero-Americana de Estudos em Educação, Araraquara, v. 14, n. esp. 4, p. 1924-1943, dez., 2019. E-ISSN: $1982-5587$. 
HORKHEIMER, 1947), a estrutura social e os instrumentos são utilizados pelos sujeitos economicamente mais fortes para dominar as massas.

Os meios de comunicação como o rádio, cinema e revistas foram transformados em negócios, [...] eles a utilizam como uma ideologia destinada a legitimar o lixo que propositalmente produzem" (ADORNO; HORKHEIMER, 1947, p. 57). A crítica ao esclarecimento se deu pela defesa dos autores de que a liberdade e pensamento esclarecedor são indissociáveis. "A crítica aí feita ao esclarecimento deve preparar um conceito positivo do esclarecimento, que o solte do emaranhado que o prende a uma dominação cega" (ADORNO; HORKHEIMER, 1947, p. 4). Portanto, a concepção de esclarecimento dos filósofos frankfurtianos avança em relação ao esclarecimento kantiano, enfatizando a necessidade de conservar a liberdade, ampliá-la e desdobrá-la. Nas implicações para a educação, surge a possibilidade de haver um ensino realmente emancipatório, que se direcione à contradição das imposições da sociedade administrada.

$\mathrm{Na}$ intenção estabelecer uma formação de sujeitos críticos e autônomos para transformação da realidade em que estão inseridos, a partir da ruptura com o modelo tradicional de ensino da Educação Física Escolar, Elenor Kunz (1991) idealizou uma perspectiva para Educação Física denominada Crítico-Emancipatória, baseada nas contribuições dos filósofos da Escola de Frankfurt, como a categoria de emancipação e esclarecimento. A proposta de Kunz teve como objetivo garantir uma educação direcionada ao pensamento crítico e formação de sujeitos autônomos para transformação da realidade em que estão inseridos, compartilhando das contribuições frankfurtianas para romper com a racionalidade instrumental presente na Educação Física. Durante a história do ensino da Educação Física na escola, os seus conteúdos exerciam papeis relativos aos interesses sociais do período. Nesse contexto, o esporte constituiu um espaço privilegiado, tendo dominância nas aulas, por se tratar de um fenômeno social, cultural, econômico e político. Na contemporaneidade, o esporte se tornou um espetáculo, apropriado pela Indústria Cultural para potencializar o consumo e, assim, “[...] se configura na sociedade contemporânea como um fenômeno pautado na busca de lucros e no seu caráter heterogêneo" (MARQUES; GUITIERREZ; ALMEIDA, 2008, p. 43).

Para transformar as aulas de Educação Física em um espaço de construção de conhecimento e de emancipação humana por meio das práticas corporais, distanciando-se assim da racionalidade instrumental estabelecida até então, a teoria crítico-emancipatória foi elaborada e é organizada em três competências, a saber: I) a competência objetiva, que visa desenvolver a autonomia do estudante por meio da técnica; II) a competência social, referente aos conhecimentos e esclarecimentos que os estudantes devem adquirir para entender o próprio RIAEE - Revista Ibero-Americana de Estudos em Educação, Araraquara, v. 14, n. esp. 4, p. 1924-1943, dez., 2019. E-ISSN: $1982-5587$. DOI: https://doi.org/10.21723/riaee.v14iesp.4.12919 
contexto sociocultural; e III) a competência comunicativa, que possibilita o processo reflexivo responsável por desencadear o pensamento crítico que ocorre através da linguagem, podendo ser de caráter verbal, escrita e/ou corporal (KUNZ, 1998). Como o esporte foi - e ainda é hegemônico como conteúdo de ensino nas aulas de Educação Física, a proposta de Kunz enfatiza a problematização do ensino do esporte e a abertura para outras práticas corporais, possibilitando aos estudantes a saída do estado de alienação para uma formação crítica rumo a autonomia continuamente dificultada pela maneira em que a sociedade capitalista encontra-se estruturada.

\section{Trabalho Docente na Educação Física Escolar: da alienação ao esclarecimento}

Conforme já mencionado, Elenor Kunz apropriou-se de conceitos da Teoria Crítica para problematizar e apresentar a importância da Educação Física na escola e, sobretudo, os desafios a serem superados com vistas a possibilidade de que possa haver um ensino emancipatório, dentre eles "o simples desenvolvimento de habilidades técnicas do esporte[...]" (KUNZ, 1991, p. 36). Isso quer dizer, que a técnica não pode ter um fim em si mesma, mas precisa ser concebida como um suporte para a compreensão e para o esclarecimento. Ghiraldelli Jr. (2007) afirma que as transformações modernas e pós-modernas, trouxeram uma concepção que passou a assimilar o corpo à máquina, assim, defende que a educação não pode estabelecer em seus processos de ensino o treinamento e adestramento de corpos, pois são formas de controlar, de inculcar valores que parecem inquestionáveis.

A predominância do caráter esportivista tornou o esporte o conteúdo hegemônico na Educação Física, limitando a aprendizagem e experiências de outros conhecimentos dos núcleos de Ginástica, Jogos e Brincadeiras, Lutas, Dança e Corporeidade. Kunz (1989) explica que capacidades de expressão, de criatividade e de comunicação que integra outras atividades de movimento não são exploradas se as aulas de Educação Física contemplarem apenas o conteúdo esportivo.

A valorização do esporte possui influência dos Jogos Olímpicos, que até a década de 1930 era um campo ético, em que o “jogo limpo" fazia parte da cultura das competições esportivistas. Conforme elucida Mostaro (2012), o evento era de cunho não-político, porém, Adolf Hitler se utilizou do momento para realizar propagandas que divulgavam o nazismo e demonstravam a força da Alemanha após a Primeira Guerra Mundial. Conteúdos como a superioridade da raça ariana e a força do Estado Alemão eram divulgados pelos meios de comunicação.

RIAEE - Revista Ibero-Americana de Estudos em Educação, Araraquara, v. 14, n. esp. 4, p. 1924-1943, dez., 2019. E-ISSN: 1982-5587. 
Os corpos dos atletas evidenciavam o treinamento e a beleza grega, tinham o dever de servir o Estado para vencer, "[...] a propaganda nazista começava a associar o sacrifício do atleta com o sacrifício humano dentro de um contexto bélico de uma guerra, explorando uma tradição de que morrer no campo de batalha era uma honraria para qualquer antepassado germânico" (MOSTARO, 2012, p. 102). Tais características se assemelham com as da Indústria Cultural como a valorização da competição, da eficiência e do belo. O mesmo sentido é considerado por Kunz (1994), ao comparar o esporte de rendimento com as sociedades industriais, na lógica de exclusão do homem pela automatização e mecanização dos novos aparelhos de produção que os tornam submissos à máquina, impossibilitam as iniciativas próprias e criativas. Porém, no caso do esporte, o homem não é substituído pela máquina, o grande espetáculo é que ele se transforma em uma máquina, com rendimentos de alta performance.

O impacto social do esporte para a sociedade é tão relevante que se torna um instrumento político com fins favoráveis aos governos, possibilitando a determinação de suas ideologias. No Brasil não foi diferente, no período da Ditadura Militar, quem ministrava as aulas de Educação Física eram instrutores do exército e reproduziam os métodos disciplinadores e hierárquicos dos militares, por essa razão, a Educação Física ainda carrega resquícios de autoritarismo por parte dos professores formados na época. Daí a relevância da discussão relativa à perspectiva emancipatória, que possibilita transcender os limites, ir além da mera repetição. “[...] manipulação direta da realidade pelo simples explorar e experimentar de possibilidades e propriedades dos objetos." (KUNZ, 1994, p. 117). A transcendência de limites é possível a partir da incorporação das formas culturalmente estruturadas das práticas corporais. O sujeito ultrapassa a reprodução dos movimentos apreendidos, podem criar movimentos, jogos e práticas corporais que tenham sentido e que contribuam para o desenvolvimento humano. A humanidade elaborou inúmeras manifestações culturais, como as manifestações corporais, que fazem parte da cultura e da vida humana, não podem ser negligenciados pela escola. Conforme consta na Lei de Diretrizes e Bases da Educação em seu Art. 26, inciso $3^{\circ}$ a Educação Física é um componente curricular obrigatório. Sendo assim tem a função de garantir aos estudantes o acesso a esses conhecimentos a partir de um ensino significativo.

A relação de se-movimentar com a subjetividade humana é fundamentalmente uma relação de sensibilidade, pois a prática de exercícios repetitivos retira significados individuais nas realizações humanas: na Educação Física, o sentido da aula deve ser o de um ensino de libertação das falsas ilusões, por meio da concepção crítica e pelo questionamento crítico dos alunos (TAFFAREL; MORSCHBACHER, 2013, p. 51). 
A concepção de Educação Física constituída pela cultura - presente até hoje - é representada como uma área de atividade, de lazer, como um momento de descanso das outras disciplinas. Esses fatores afetam a busca pela legitimidade dessa disciplina na escola, para a consolidação da concepção de área de conhecimentos tão importante para a formação dos sujeitos como as disciplinas legitimadas. De fato, os professores contribuíram para essa cultura e, do mesmo modo, são responsáveis pela transformação da concepção tradicional. Por essa razão, o trabalho docente precisa ser intencional e planejado, a fim de que aulas possam efetivamente proporcionar aos estudantes uma aprendizagem significativa e, por meio do movimento humano e das práticas corporais, que possam conhecer, explorar, experimentar diversas possibilidades de sua corporeidade e, sobretudo, se aproximar cada vez mais da emancipação humana.

\section{Considerações finais}

A educação constitui uma instância da sociedade. Sendo assim, as instituições educativas integram o contexto social, recebendo igualmente, as influências e interferências sociais. Conforme discutido no percurso teórico deste texto, a Indústria Cultural tem o domínio dos modos de vida, dos modelos de concepção de razão e de educação, a partir da transformação do ser humano em consumidor e, assim, agindo para despertar emoções e desejos que potencializem o consumo e desviam a atenção da percepção realista das estruturas sociais. Para tanto, os sujeitos devem, necessariamente, possuir uma consciência semiformada.

Isso significa que a escola, inserida no contexto capitalista, é utilizada como um instrumento de manipulação da ideologia dominante para promover um ensino para a semiformação, impedindo o desenvolvimento do pensamento crítico, logo, distanciando cada vez mais a almejada emancipação humana. Nesse contexto, ao analisar o histórico da Educação Física nos espaços escolares, percebe-se que essa disciplina esteve a serviço dos interesses da sociedade dominante, de acordo com o período histórico. $\mathrm{Na}$ atualidade continua sendo um alvo do estabelecimento do padrão estético e físico, do consumo e do controle dos corpos. As aulas baseadas na racionalidade instrumental, não possibilitam a tomada de consciência, o reconhecimento do próprio corpo e do outro; há também influências nas relações sociais, a interação entre os estudantes, principalmente entre os jovens vem sendo problemática com conflitos, discriminação e bullying, dificultando a formação autônoma e a capacidade de refletir criticamente, assim, conforme Adorno já sinalizava, a educação que não ensina para o 
pensamento crítico, gera um sujeito com personalidade autoritária e, consequentemente, a manutenção da barbárie.

Nesse sentido, consideramos a importância da ação do professor para a superação do ensino enraizado na razão instrumental, por meio do trabalho docente intencional e planejado com vistas ao desenvolvimento do pensamento crítico dos sujeitos. Com a proposta da Teoria Crítico-Emancipatória elaborada por Elenor Kunz, pautada na Teoria Crítica da Sociedade, encontramos possibilidades para o ensino da Educação Física na escola romper com o modelo tradicional esportivista, constituído por um caráter disciplinador voltado para o alto rendimento, padronização de corpos e comportamento, bem como com a concepção de área de atividade.

Portanto, defendemos que o processo educativo precisa conceber o ensino das habilidades técnicas, juntamente com criticidade para proporcionar aos estudantes uma aprendizagem significativa, com o ensino dos conhecimentos científicos da cultura corporal, com experiências do movimento humano e das práticas corporais para que possam conhecer, explorar, experimentar diversas possibilidades de sua corporeidade e, sobretudo, se aproximar cada vez mais da emancipação humana. Desse modo, pretendemos abrir um caminho para se pensar um ensino que saia da alienação para o esclarecimento.

\section{REFERÊNCIAS}

ADORNO, T.; HORKHEIMER, M. Dialética do esclarecimento: fragmentos filosóficos. Tradução Guido Antonio de Almeida. Rio de Janeiro: Jorge Zahar Ed., 1985.

ALTHUSSER, L. Aparelhos Ideológicos de Estado. 3. ed. Rio de Janeiro: Edições Graal, 1987.

ARAÚJO, K. de T. Transformações Sociais, Desenvolvimento Tecnológico e a Educação na Contemporaneidade. In: EDUCERE - XI Congresso Nacional de Educação. 2013, Curitiba, Anais... Curitiba: EDUCERE, p. 5164-5184, 2013.

BRASIL. Ministério de Educação e Cultura. LDB - Lei $\mathbf{n}^{\mathbf{0}}$ 9394/96, de 20 de dezembro de 1996. Estabelece as diretrizes e bases da Educação Nacional. Brasília: MEC, 1996.

BERTE, O. S.; MARTINS, R. Corpo e Educação: desconstruindo imagens para reconstruir pedagogias. Revista Educação e Cultura Contemporânea, v. 13, n. 32, 2016.

BUENO, S. F. Semicultura e educação: uma análise crítica da revista Nova Escola. Revista Brasileira de Educação, v. 12, n. 35, p. 300-307, 2007.

COSTA, J. H. A atualidade da discussão sobre a Indústria Cultural em Theodor W. Adorno. Trans/Form/Ação: Revista de Filosofia, Marília, v. 36, n. 2, p. 135-154, maio/ago., 2013. 
FOUCAULT, M. Vigiar e punir: nascimento da prisão. Petrópolis: Vozes, 2004.

GHIRALDELLI JR., P. O corpo: filosofia e educação. São Paulo: Ática, 2007.

KANT, I. O que é o Esclarecimento? In: Imannuel Kant Textos Seletos. Tradução de Floriano de Souza Fernandes. 2. Ed. Petrópolis: Vozes, p. 100-117, 1985.

KUNZ, E. O esporte enquanto fator determinante da Educação Física. Contexto \& Educação, v. 15, p. 63- 73, 1989.

KUNZ, E. Transformação didático-pedagógica do esporte. Ijuí: Unijuí, 1994.

MAAR, W. L. Adorno, semiformação e educação. Educação e Sociedade. Campinas, v. 24, n. 83, p. 459-476, ago., 2003

MARQUES, R. F. R.; GUTIERREZ, G. L.; ALMEIDA, M. A. B. de. O esporte contemporâneo e o modelo de concepção das formas de manifestação do esporte. CONEXÕES Revista da Faculdade de Educação Física da UNICAMP, Campinas, v. 6, n. 2, 2008 - ISSN 1983-9030.

MOSTARO, F. F. R. Jogos Olímpicos de Berlim 1936: o uso do esporte para fins nada esportivos. Comunicação e Entretenimento: Práticas Sociais, Indústrias e Linguagens. v. 19, n. 1, p. 95-108, 1. Semestre, 2012

PUCCI, B. Teoria crítica e educação: contribuições da teoria crítica para a formação do professor. Espaço Pedagógico, v. 8, p. 13-30, 2001a.

PUCCI, B. Um encontro de Adorno e Nietzsche na mínima moralia. Editora UNIMEP, artigo, v. 10, 2001b.

PUCCI, B. Tecnologia, crise do indivíduo e formação. Comunicações (Piracicaba), Piracicaba-SP, v. 2, p. 70-80, 2005.

SOARES, C. L. et al. Metodologia do ensino de Educação Física. São Paulo: Cortez, 1992.

TONET, I. Educar para a cidadania ou para a liberdade? Perspectiva, v. 23, n. 2, 469-484. Jul./dez., 2005.

ZUIN, A. Á. S. Sobre a atualidade do conceito de indústria cultural. Cadernos Cedes, v. 21, n. 54, p. 9-18, 2001. 


\section{Como referenciar este artigo}

SANTOS, Flávia Regina Schimanski dos; OLIVEIRA, Fernanda Neri; ARAÚJO, Karina de Toledo. Indústria Cultural e a Dialética do Esclarecimento: implicações para o trabalho docente na Educação Física Escolar. Revista Ibero-Americana de Estudos em Educação, Araraquara, v. 14, n. esp. 4, p. 1924-1943, dez., 2019. E-ISSN: 1982-5587. DOI: https://doi.org/10.21723/riaee.v14iesp.4.12919

Data de submissão: $25 / 06 / 2019$

Data de aceite: 25/08/2019

Data de publicação: 01/09/2019 